\title{
O PAPEL DA CARTOGRAFIA TEMÁTICA NAS PESQUISAS AMBIENTAIS
}

Janine Gisele Le Sann ${ }^{1}$

\begin{abstract}
Resumo: Apresenta-se a Cartografia como linguagem de representação de fatos e fenômenos geográficos. A Cartografia Temática possui especificidades que interferem no processo de tradução visual de uma informação geográfica. Atenta-se para a necessidade do cartógrafo conhecer a linguagem gráfica e os limites da representação bidimensional, escolhendo variáveis visuais compatíveis com o significado intrínseco da informação a ser traduzida. Analisa-se documentos e sugere-se a realização de correções gráficas de legendas segundo a Semiologia Gráfica. Descreve-se o método para a estruturação de legenda de mapa politemático, sintético, aplicado ao estudo de caso do mapa diagnóstico geoambiental da Usina Hidrelétrica de Igarapava.
\end{abstract}

Palavras-chave: Cartografia Temática, Pesquisas ambientais, Semiologia Gráfica, Cartografia do meio ambiente.

\section{Introdução}

No final do século $X X$, a introdução das ferramentas computacionais nas diversas áreas da pesquisa deu um novo impulso aos estudos do espaço geográfico. Houve uma verdadeira revolução nas técnicas cartográficas: passou-se da caneta à tinta nanquim para 0 mouse do computador. Diversos programas de desenho gráfico como o AutoCad foram aprimorados, facilitando 0 desenho por meio da cartografia automatizada. Programas específicos da cartografia foram desenvolvidos sob um novo conceito: 0 dos Sistemas de Informação Geográfica (SIG). Pensouse que os SIGs substituiriam a cartografia temática, todavia, tratase de dois conceitos de representações espaciais completamente diferentes.

Os elementos espaciais na cartografia temática são representados por meio de documentos, sejam analíticos, sejam sintéticos, frutos do pensamento e das escolhas de um especialista.

0 produto gráfico de um SIG resulta da superposição de níveis de informações que ocupam um mesmo espaço, na íntegra ou parcialmente, agregando-se um peso ou um significado, frutos do pensamento e das escolhas de vários especialistas. 0 documento final apresenta uma síntese de todos os pesos ou significados atribuídos pelos diversos especialistas. Isso significa que duas representações semelhantes podem ter significados diversos; apenas suas resultantes ficaram iguais. Assim, um ponto de peso 5 , por exemplo, pode ser a resultante de $3+2+0$, ou $1+2$ +2 , ou ainda, $0+2+3$, etc. Por isso, um produto de SIG não pode ser visto como um mapa temático. 0 leitor precisa entender os diversos pesos e suas possíveis combinações.
A cartografia automatizada não passa de uma caneta sofisticada. 0 trabalho de estruturação de uma legenda continua indispensável. 0 computador faz 0 que 0 operador manda fazer, não pensa, nem analisa o documento final.

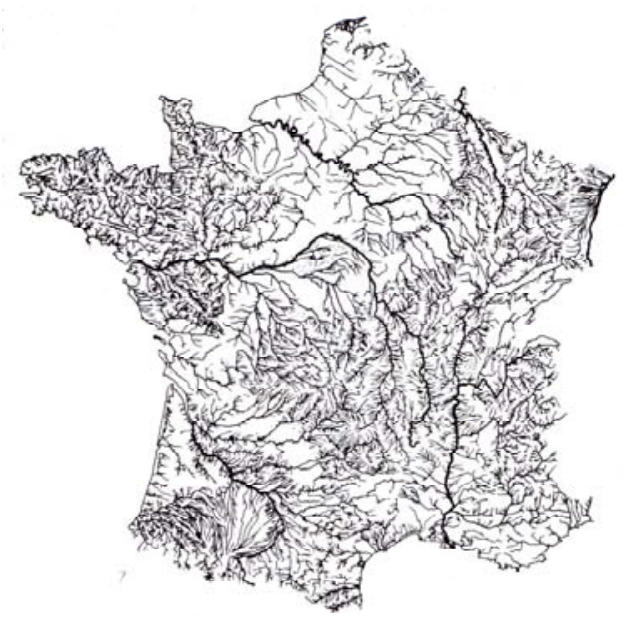

Figura 1 Os rios na França. Fonte: BERTIN (1967:153).

No livro Os métodos da geografia, Pierre GEORGE explicava que "a geografia é o estudo de um espaço contínuo. [...] A geografia pretende atingir a exaustividade espacial de seu objeto na medida em que seu modo de expressão específica é o mapa" (1970:10).

A carta dos rios, na França (Fig. 1), dispensa uma legenda já que 0 desenho dos rios revela as bacias. Para o leigo, essa carta mostra as quatro principais bacias presentes no território francês, sua amplitude, quantidade de afluentes, comprimento e densida-

1 Centro Universitário UNA jlesann@hotmail.com 
de dos cursos de água. 0 especialista infere informações sobre a geologia, o relevo, a importância histórica e sócio-econômica da bacia, entre outras coisas. A informação representada se limita a responder as perguntas "O quê?", "Onde?".

Uma carta representa as posições e formas dos objetos reais, por meio da latitude e da longitude, às vezes, altitude ou profundidade, portanto, com precisão de localização. É o domínio das cartas topográficas, náuticas e aeronáuticas.

\section{A cartografia temática}

A cartografia é chamada temática quando traz significados além da trilogia latitude, longitude, altitude.

A cartografia (temática) é o instrumento de expressão dos resultados adquiridos pela geografia, mas, ela própria é uma técnica que pode ser aplicada para projetar no espaço qualquer noção ou ação que se torne necessária representar espacialmente sem que essa noção ou ação faça parte de um sistema de relações geográficas. (GEORGE, 1970).

A cartografia temática representa temas diferentes com ou sem expressão física no espaço. Idéias abstratas podem ser representadas por meio de mapas, por exemplo, as áreas de influência de cidades, a densidade populacional, a produtividade de uma cultura, entre uma infinidade de temas.

Todavia, o desconhecimento das propriedades dos símbolos utilizados para traduzir visualmente as informações pode produzir imagens falsas (Fig. 2 mapa da esquerda).

0 mapa representa 0 rendimento da cultura do trigo na França, em 1973, portanto, traz uma informação com significado de quantidade (de menos de 3500 até mais de 5000 toneladas). As quantidades, expressas em classes, são naturalmente ordenadas, da menor (na classe inferior da legenda) para a maior (na classe superior dessa mesma legenda).

Na Fig. 2, no mapa da esquerda, a variável visual escolhida para a tradução visual (a tonalidade ou valor) não está ordenada conforme as variações das classes que compõem a legenda, ou seja, a informação quantitativa ordenada está representada por uma variável visual desordenada.

Esse é 0 exemplo de uma legenda errônea que pode levar a uma análise equivocada. Nem sempre 0 erro é tão claro quanto neste exemplo, todavia, trata-se de um erro muito comum.

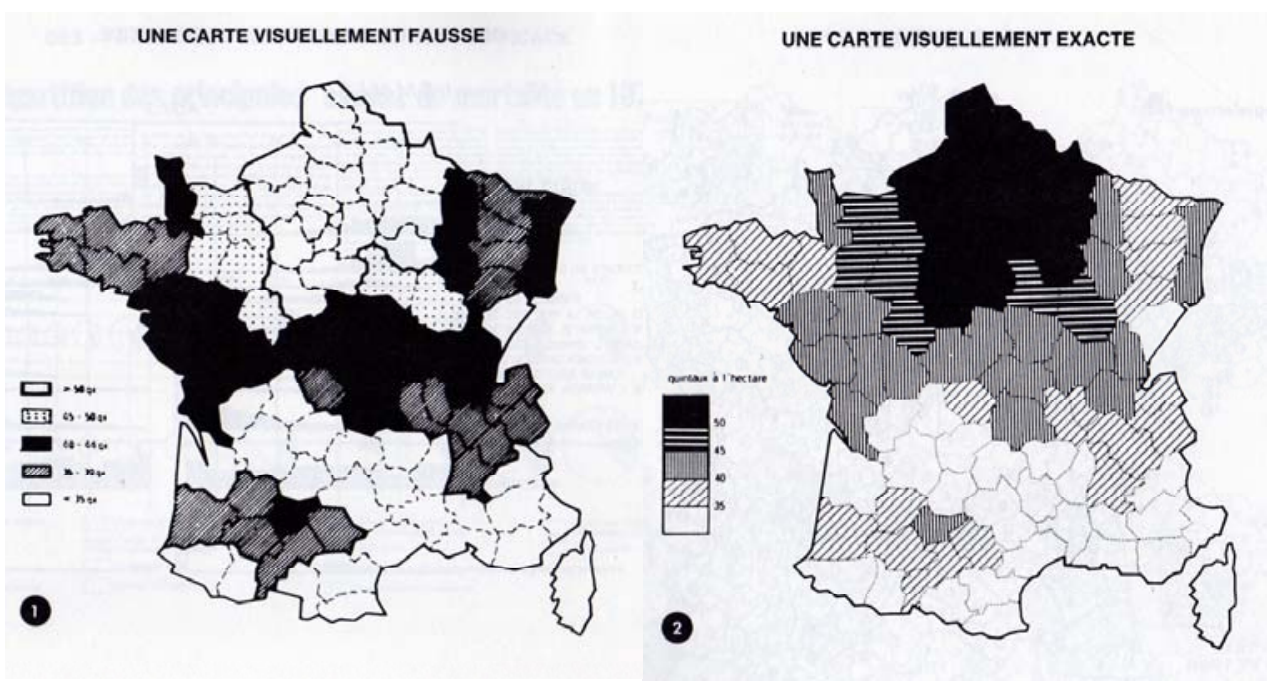

Figura 2 Um mapa falso (esquerda) e o mapa certo (direita). Fonte: BONIN (1989:25).

Obrigar o leitor a ler e memorizar os símbolos de uma legenda leva-o a reconstruir mentalmente 0 mapa. Nesse caso, 0 mapa vai ser lido e não visto. Ora, a superioridade da imagem sobre 0 texto encontra-se na característica de sua apreensão global e imediata. A imagem se impõe ao leitor que a memoriza automaticamente. No exemplo da cultura do trigo na França, a imagem falsa é gravada na memória do leitor. A reconstituição mental da imagem certa, no caso do leitor perceber o erro da legenda (o que, raramente acontece), não produzirá uma imagem memorável para substituir a imagem errada. 
A Fig. 3 superior representa uma informação quantitativa $e$ sua tradução por meio da variável visual forma. As classes da legenda variam de menos de $0,05 \mathrm{mg}$ por litro até mais de $0,5 \mathrm{mg}$ por litro. Fica impossivel localizar os trechos de cursos de água com maior nivel de poluição por fosfatos sem recorrer à legenda, uma vez que a variável visual forma escolhida para traduzir 0 significado da legenda não mostra quantidade mas diferenças.

Na Fig. 3 inferior, os mesmos dados estão representados por meio da variável visual tamanho, o que evidencia as relações existentes entre os dados.
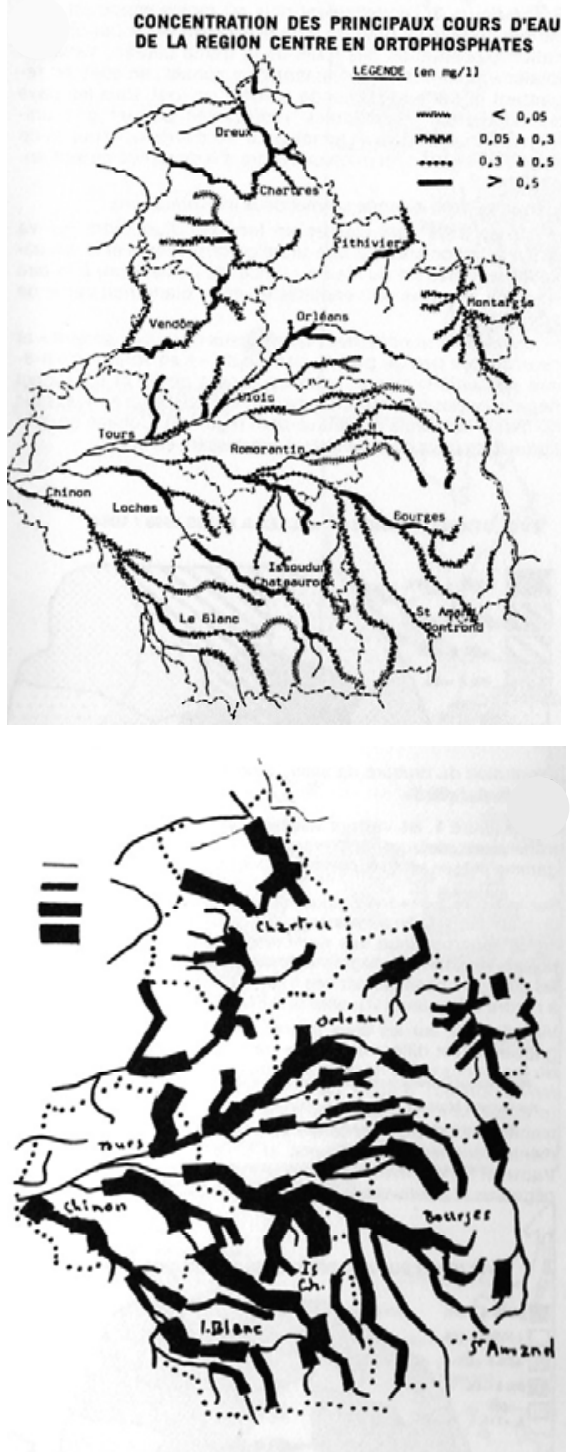

Figura 30 uso equivocado da variável visual forma (superior) e mesma informação representada com a variável visual tamanho (inferior). Fonte: BONIN (1989:107).
Dados com significado de ordem devem ser representados por uma ordem. No mapa da Fig. 4 há uma hierarquia de aldeias em quatro níveis de classificação. Pontos de tamanhos diferentes, ordenados, acompanham a ordem do significado da informação. A leitura imediata do mapa não deixa dúvidas quanto à distribuição espacial das aldeias. Portanto, 0 uso da variável tamanho está correto.

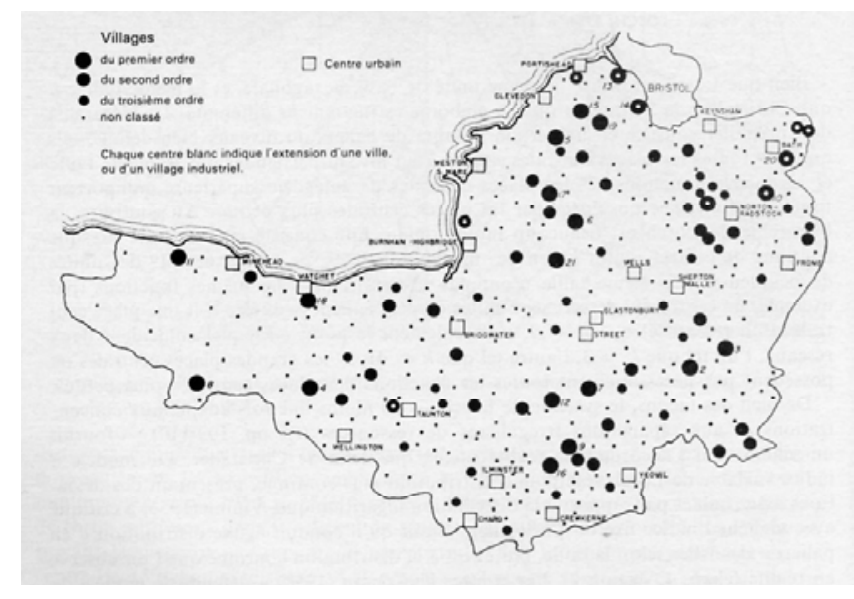

Figura 4 Representação de dados ordenados. Fonte: HAGGETT (1973:142).

Verificou-se, então, que a variável visual deve expressar a lógica de significado da informação mapeada. Trata-se de uma verdadeira tradução de linguagens: da linguagem escrita para a linguagem gráfica. Ambas possuem gramáticas. No caso da linguagem gráfica, a gramática é a Semiologia Gráfica sistematizada por BERTIN no livro Sémiologie Graphique, publicado em 1967.

\section{A semiologia gráfica}

0 respeito às relações existentes entre os dados de uma mesma informação constitui a base conceitual da Semiologia Gráfica. Assim, uma informação quantitativa precisa ser traduzida por meio de uma variável visual quantitativa. Uma informação ordenada, por meio de uma variável ordenada.

A folha de papel apresenta limitações. O espaço real, tridimensional por natureza, é representado nas duas dimensões do plano da folha de papel. A posição geográfica dos elementos geográficos, localizada por meio de latitude e longitude, é representada na largura e no comprimento do plano: trata-se do mapa base ou, ainda, do fundo de mapa. 0 tema é traduzido por símbolos chamados, em Semiologia Gráfica, variáveis visuais.

BERTIN reconheceu seis variáveis visuais: tamanho, 
tonalidade (valor), cor, forma, orientação e granulação. Todavia, apenas as quatro primeiras são utilizadas com maior freqüência.'

Essas variáveis visuais podem ser utilizadas em pontos, linhas ou áreas (zonas). São os chamados modos de implantação da Semiologia Gráfica: pontual, linear ou zonal. A determinação do modo de implantação pertinente para uma determinada informação depende da própria informação. Assim, uma cidade será representada por um ponto ou uma área, dependendo da escala de representação. Rios, limites e vias serão representados por linhas, densidades e quaisquer informações, ocupando uma área, no modo de implantação zonal.

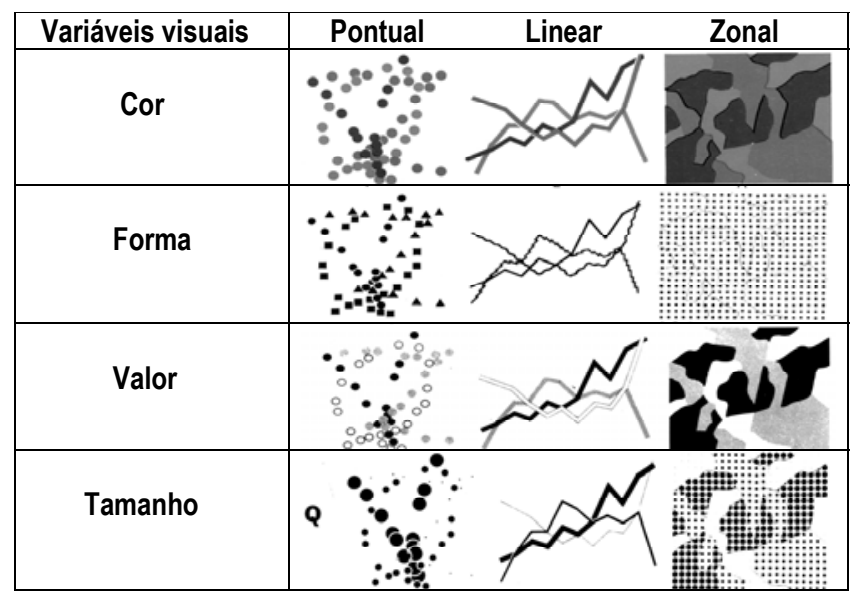

Figura 5 Variáveis visuais e os modos de implantação. Fonte: BERTIN, (1967:66).

Em síntese, as ferramentas disponiveis para traduzir as relações de significado de qualquer informação são:

a) as duas dimensões do plano, mobilizadas pelo mapa base;

b) quatro variáveis visuais: tamanho, tonalidade, cor e forma, determinadas pela relação de significado entre os dados;

c) três modos de implantação: pontual, linear ou zonal.

A Fig. 5 ilustra as combinações possíveis entre variável visual e modo de implantação.

\begin{tabular}{|l|c|c|c|}
\hline \multirow{2}{*}{ Variável visual } & \multicolumn{3}{|c|}{ Nível de organização } \\
\cline { 2 - 4 } & Seletivo & Ordenado & Quantitativo \\
\hline Forma & $\mathbf{= l}=$ & & \\
\hline Cor & $\mathbf{= l}=$ & & \\
\hline Tonalidade & & $\mathbf{0}$ & \\
\hline Tamanho & & 0 & $\mathbf{Q}$ \\
\hline
\end{tabular}

Figura 6. Níveis de organização das variáveis visuais. Fonte: BERTIN, (1967:76).
Os exemplos anteriores demonstram que cada variável visual possui a propriedade de representar um determinado significado: os níveis de organização da Semiologia Gráfica. A Fig. 6 apresenta os níveis de organização das variáveis visuais, ou seja, os significados que cada variável visual traduz.

A variável forma foi utilizada na Fig. 3 superior para representar uma informação cujo nível de organização é quantitativo. Por isso, o leitor não percebe a relação de quantidade entre os dados.

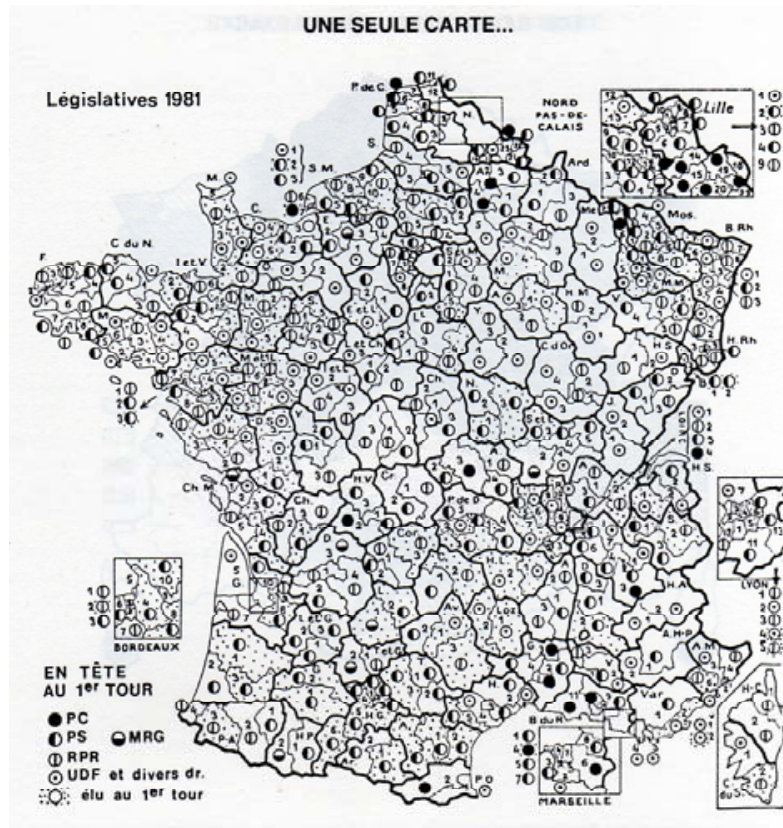

OU PLUSIEURS CARTES ?
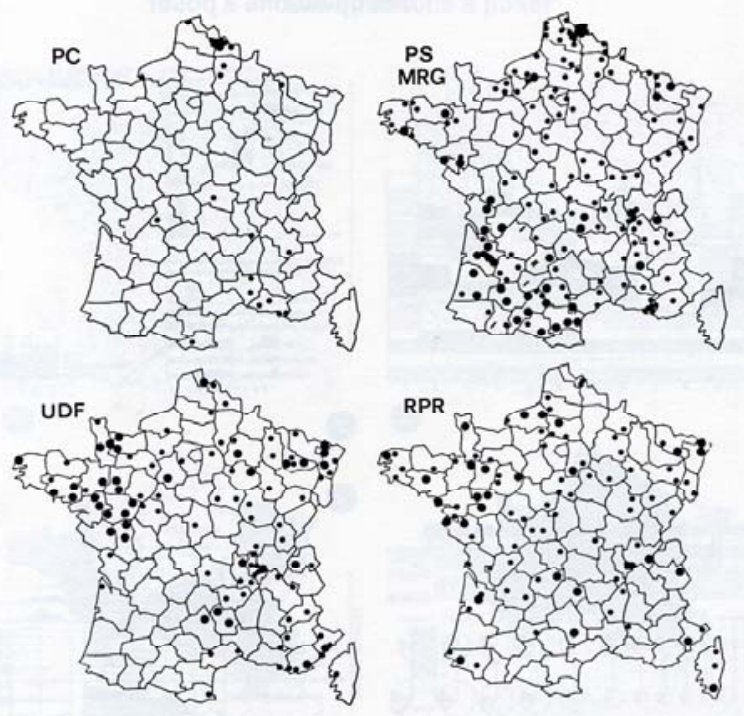

Figura 7 Um mapa (superior) ou vários mapas (inferiores). Fonte: BONIN (1989:23). 


\section{As limitações do plano}

A densidade de informações que uma folla de papel suporta é limitada. Às vezes, a melhor solução gráfica exige separar as informações por partes, para melhor representá-las (Fig. 7).

No caso de informações analíticas, a divisão é recomendada. A geografia dos partidos políticos franceses aparece claramente. 0 leitor pode comparar as distribuições regionais.

Quando se trata de um documento sintético, a superposição é indispensável. Neste caso, um estudo rigoroso de legenda se torna necessário.

\section{Método de elaboração da legenda de mapa politemático}

Um mapa da cidade francesa de Nantes foi elaborado para dar suporte à tomada de decisão dos vereadores com relação à renovação de uma parte da cidade. 0 documento original apresenta-se bastante confuso e ilegível (Fig. 8 superior). Baseado na Semiologia Gráfica, BONIN (1989) reorganizou a legenda, respeitando a lógica das informações e escolhendo cuidadosamente as variáveis e os símbolos de cada variável. Este trabalho originou 0 quadro da Fig. 8 intermediário. 0 novo mapa (Fig. 8 inferior) evidencia a relevância deste procedimento.

Todos os dados que compõem a legenda são seletivos. Para estruturar o quadro que deu origem à legenda (Fig 8 intermediário), os dados (caracteres) foram agrupados em categorias. 0 número de ocorrências, o tipo de símbolo e o modo de implantação foram discriminados de modo a compará-los entre si e avaliar seu nível de diferenciação. Apesar de próximos, os símbolos de uma mesma família devem ser seletivos entre si e, ainda, ser percebidos como nitidamente pertencentes a essa família. Testes diversos precisam ser feitos, considerando o número de ocorrências e adequando 0 tamanho dos símbolos à proporção da escala. É notável que, geralmente, os símbolos utilizados são muito pequenos e bastante semelhantes, o que dificulta muito sua diferenciação e associação.

No mapa original há uma "imagem parasita", ou seja, o mapa foi desenhado em cima de um fundo no qual existiam ruas e nomenclaturas ilegíveis. Este problema foi corrigido na nova solução.

CARMO (1994) aplicou este método ao estudo da legenda para o mapa diagnóstico geoambiental da usina hidrelétrica de Igarapava. 0 trabalho foi desenvolvido na Universidade Federal de Minas Gerais, antes da introdução dos computadores para estudos desenvolvidos em ambiente universitário. Os testes e os desenhos finais foram realizados à mão.

Originalmente, duas versões deste mapa foram elaboradas para a Central Elétrica de Minas Gerais (CEMIG). Uma colorida e a outra em tons de cinza (Fig. 9 superior e inferior respectivamente).
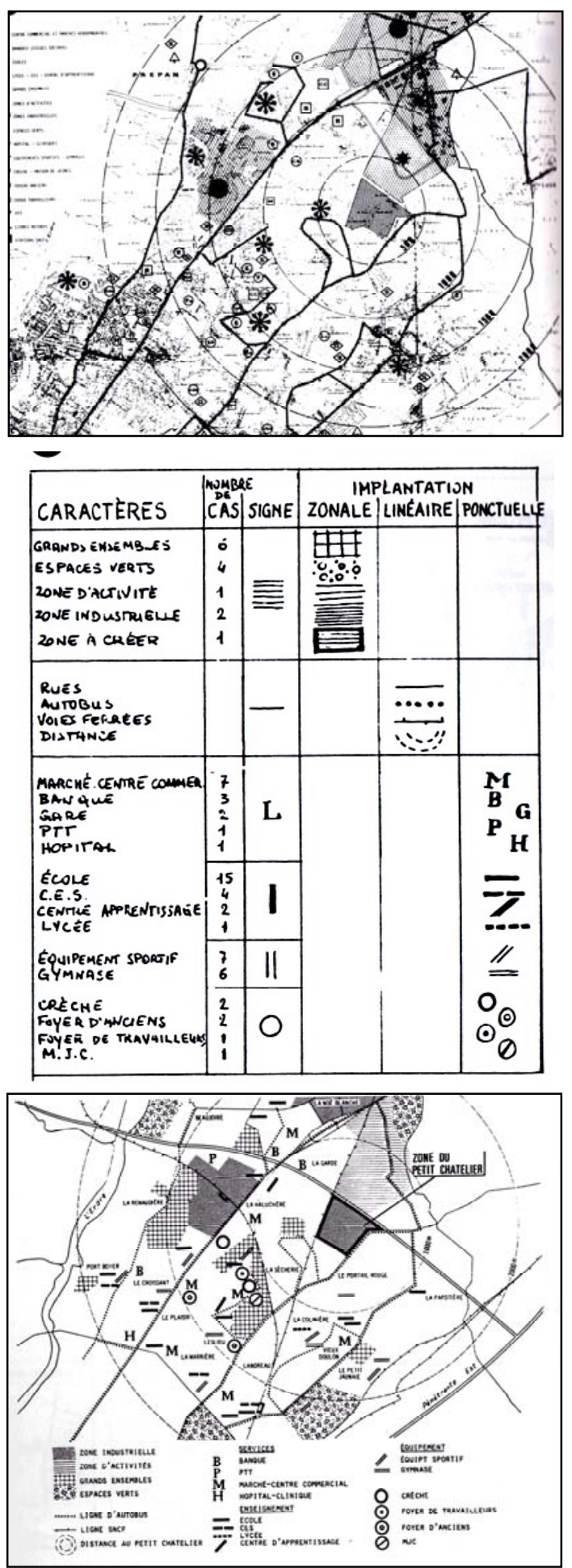

Figura 80 exemplo do mapa de Nantes. Documento original (superior) e modificado (inferior). Fonte: BONIN (1989:112 - 113). 


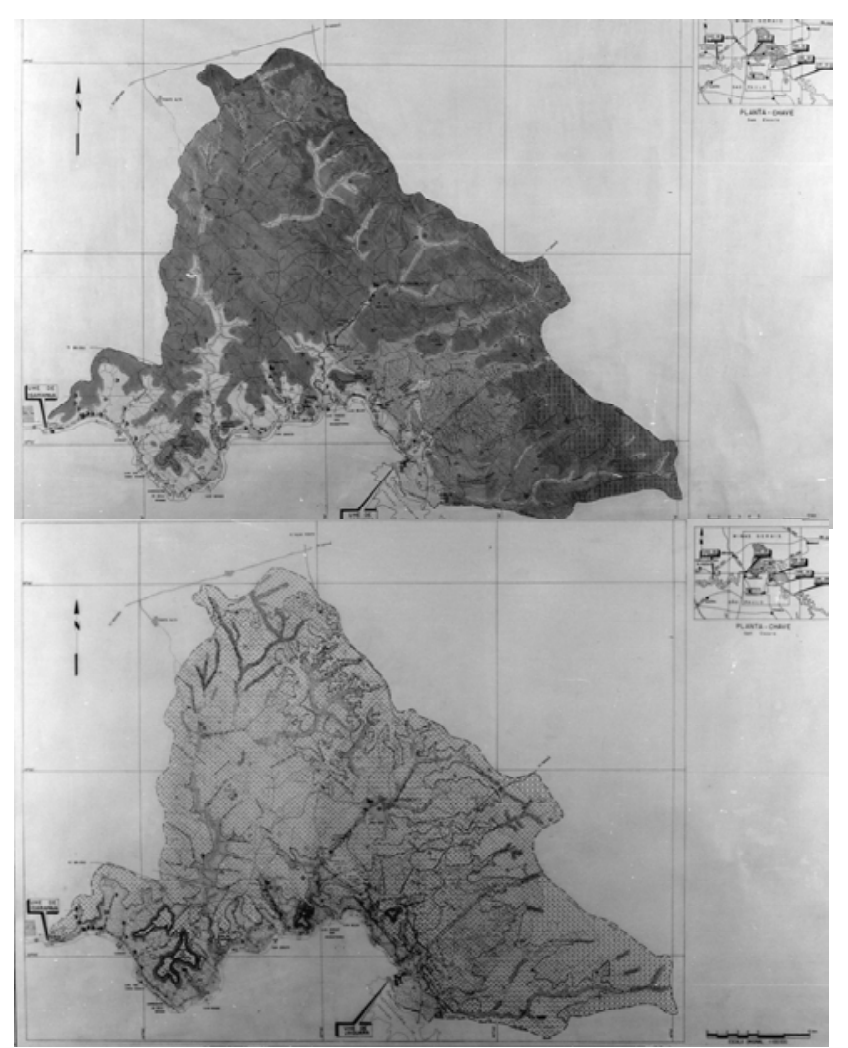

Figura 9 Partes das duas versões originais do mapa diagnóstico geoambiental da usina hidrelétrica de Igarapava. Versão 1 acima e Versão 2 abaixo. Fonte: CARMO (1994).

"Primeiramente, foi feita uma profunda análise das informações envolvidas na elaboração das duas versões originais do mapa em termos da identificação dos componentes e suas respectivas características. Em seguida realizou-se a avaliação das variáveis da retina empregadas na tradução, comparando as suas características (nível de organização, modo de implantação e comprimento) com as características dos componentes que elas traduzem. Finalmente, avaliou-se a legibilidade do mapa no que tange a sua resposta visual. Os critérios considerados são: a densidade gráfica, a separação angular e a separação retiniana. A legibilidade foi avaliada em dois níveis, o estudo individual da legibilidade de cada variável da retina e o estudo da legibilidade a partir da superposição de duas ou mais variáveis da retina" (CARMO, 1994).

Dos problemas diagnosticados, os mais graves foram: a baixa legibilidade de ambas as soluções gráficas, os símbolos pouco diferenciáveis e os erros na escolha de variáveis da retina.
"Os problemas de legibilidade relacionam-se principalmente â densidade gráfica elevada devido ao número significativo de símbolos representados através da superposição; ao uso de padrões (de desenho) densos; a uma separação angular deficiente causada pela existência de símbolos pouco diferenciáveis e a uma separação retiniana insuficiente em função do pouco contraste visual entre as diversas simbologias" (CARMO, 1994).

0 mapa abrange parte do Triângulo Mineiro e parte do estado de São Paulo, por isso, os originais foram feitos em duas partes. A Fig. 10 apresenta os testes realizados com o objetivo de melhorar a legibilidade dos mapas.

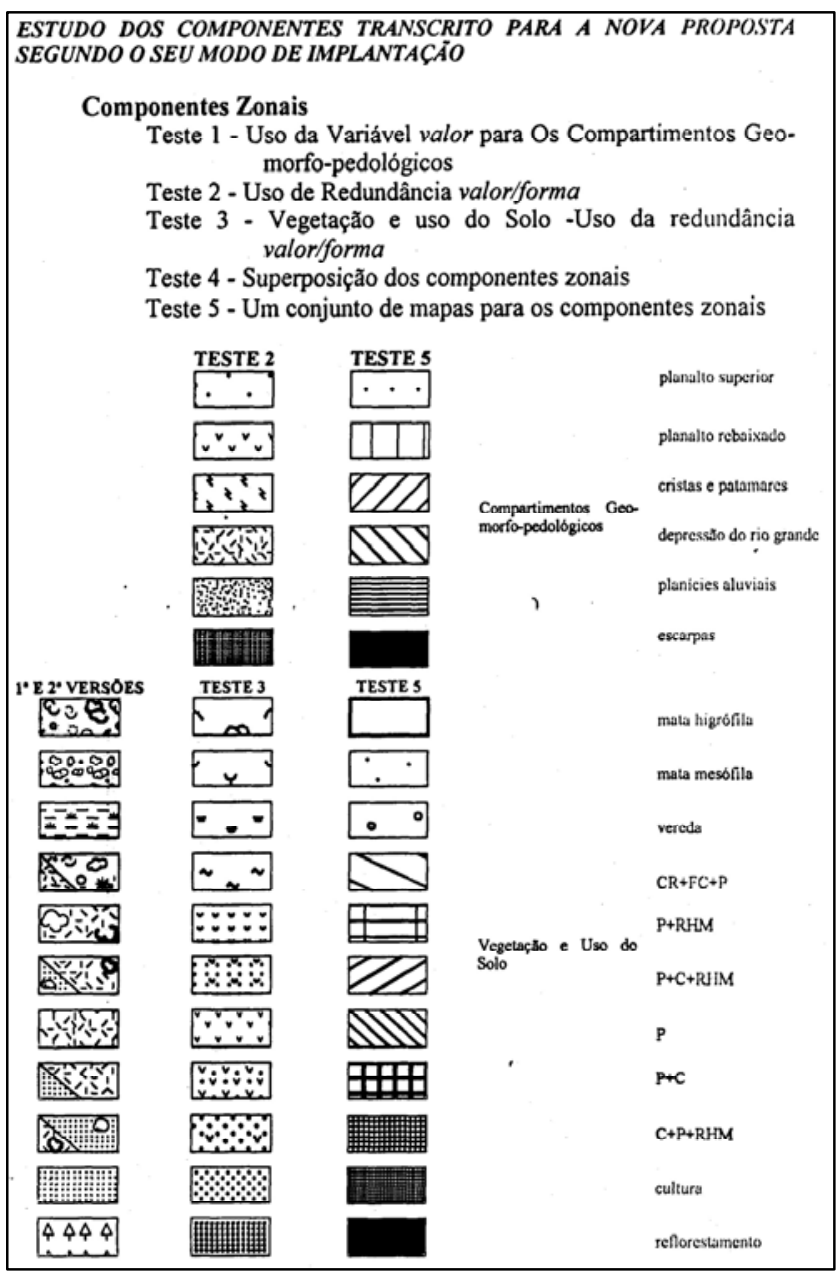

Figura 10 Testes de legenda. Fonte: CARMO (1994).

Os resultados do diagnóstico levaram a autora a procurar outra solução gráfica, junto ao Programa de Mestrado em Geografia 
da Universidade Federal de Minas Gerais.

Após diversos testes, na tentativa de melhorar a legibilidade dos mapas originais, optou-se por mudar o método e organizou-se o quadro com todos os dados da legenda (Fig. 11).

Esse trabalho foi feito para todos os temas, separando as informações por modo de implantação (pontual, linear ou zonal) e nível de organização (seletivo, ordenado ou quantitativo). Como o mapa apresenta mais de uma informação zonal, foi feito um estudo específico para possibilitar a superposição de símbolos.

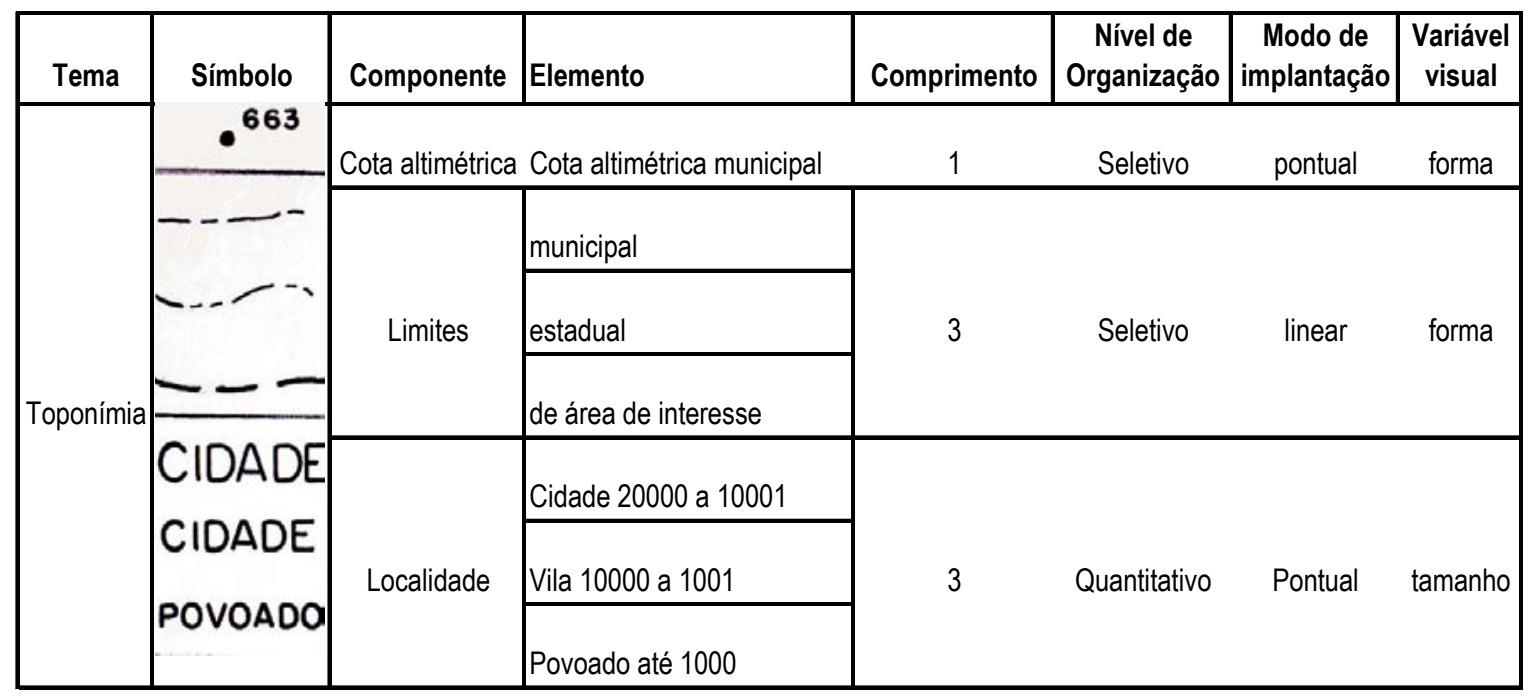

Figura 11 Parte do quadro analítico para estruturação de legenda. Fonte: CARMO (1994).

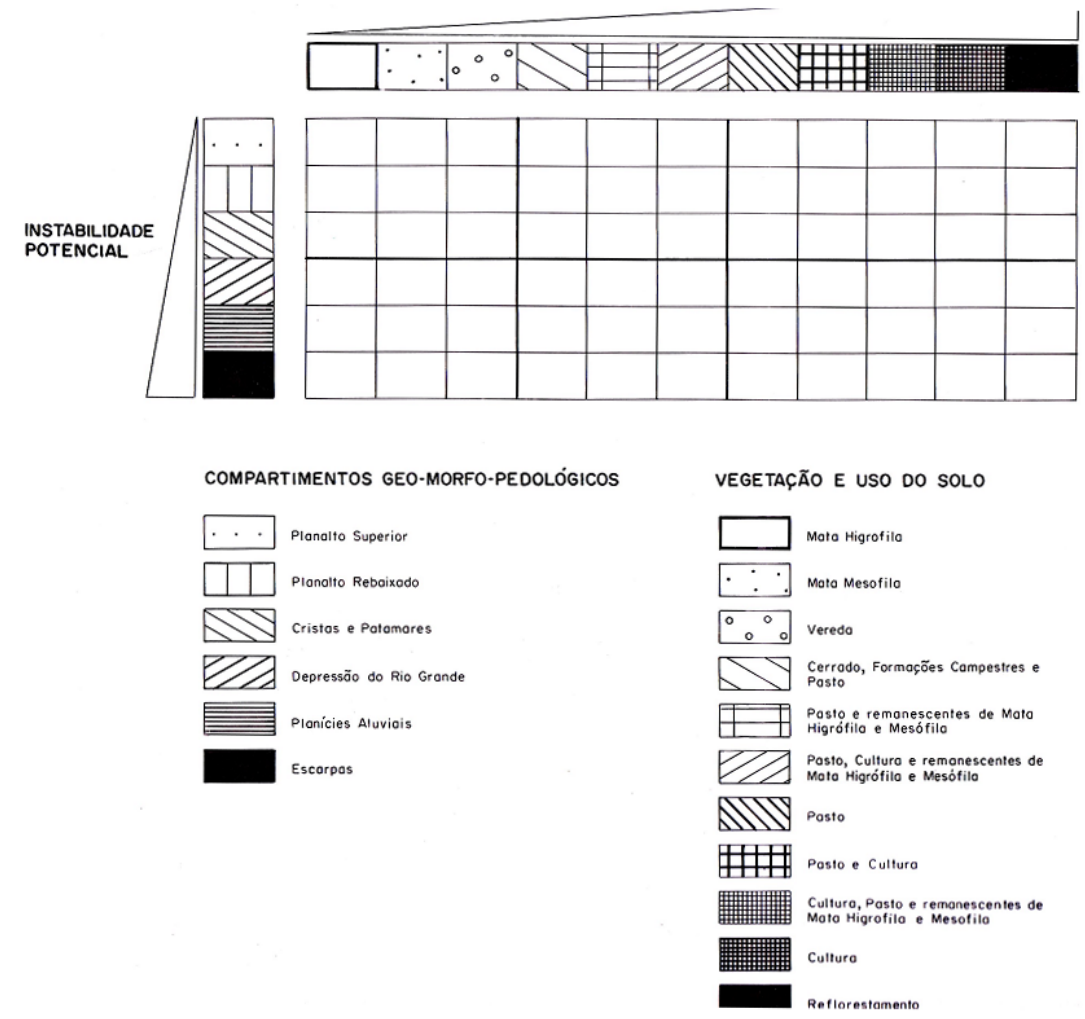

Figura 12 Exemplo de cruzamento de dados para estruturação de uma legenda sintética. Fonte: CARMO (1994). 
Após diversos testes de legenda (Fig. 10), verificou-se a necessidade de se trabalhar com mapas sintéticos de nível intermediário. Assim, os temas poluição do ar, das águas, fontes poluidoras e dinâmica de superfície foram agrupados no mapa sintético de nível intermediário intitulado Dinâmica Ambiental. Os Aspectos Culturais (patrimônio histórico, arqueológico e natural) compõem o segundo mapa. 0 mapa dos Aspectos Humanos agrupa os elementos da infra-estrutura e o patrimônio edificado. No mapa Cobertura, encontra-se a fauna, a vegetação e o uso do solo. Os dados sobre pedologia, geomorfologia e geologia foram sintetizados no mapa Suporte (Fig. 12). 0 mapa final Síntese Geoambiental é o resultado da superposição dos cinco anteriores. Optou-se por separar toda Toponímia num suporte vegetal avulso que pode ser superposto a qualquer um dos mapas.

A solução final é composta por documentos que podem ser superpostos dois a dois, seguindo um guia de leitura. Esta solução leva 0 leitor a entrar na informação aos poucos, a formular hipóteses e procurar respostas nas superposições. Tendo em vista a grande quantidade e variedade de dados, a mobilização de todos os modos de implantação e de todas as variáveis visuais, este tipo de mapa constitui-se no maior desafio do domínio da cartografia temática. A solução adotada para esse caso aponta na direção dos Sistemas de Informação Geográfica.

\section{Considerações finais}

Para BERTIN (op cit), quem trabalha com cartografia temática no contexto da Semiologia Gráfica, deve ser chamado de "redator gráfico". Com efeito, a cartografia temática, como meio de representação, leva, obrigatoriamente, 0 redator gráfico a fazer escolhas. Isto se refere ao trabalho de estruturação de uma legenda, comparável ao de um texto. Para escolher, é necessário definir critério. Definir critério significa categorizar e priorizar, pensar e entender para transmitir. Esse procedimento lembra muito 0 processo de construção de um texto, por esta razão BERTIN se refere a redação.
No caso dos estudos ambientais, isto significa, também, priorizar 0 trabalho interdisciplinar entre especialistas de áreas diferentes e complementares. Além de respeitar os critérios escolhidos no contexto de cada especialidade, é necessário respeitar a lógica de significado da informação a ser representada.

0 método utilizado nos dois exemplos anteriores objetiva levar o leitor ao entendimento progressivo das sínteses propostas, acompanhando a reflexão do redator gráfico e introduzi-lo às escolhas que foram feitas ao longo do desenvolvimento do trabalho, ou seja, convidá-lo a aprofundar o entendimento da síntese final.

A apresentação por partes, sob forma de documentos que são superpostos pelo leitor, seguindo seu raciocínio pessoal e seus interesses particulares, com possibilidade de retornar às escolhas iniciais e questioná-las para aprofundar 0 entendimento e a contextualização da síntese final, constitui a principal vantagem desse método. 0 leitor fica próximo das informações e pode "dialogar" com as representações, compreendendo todas as relações e interdependências. Esse procedimento favorece, ainda, a elaboração de novas hipóteses, a continuidade e aprofundamento da própria pesquisa.

0 principal problema da cartografia temática é 0 de requerer um trabalho manual, demorado, que demanda muita habilidade $e$ técnica do desenhista, na elaboração dos desenhos. Trabalhar com folhas de papel vegetal ou filme plástico, significa que qualquer erro de desenho implica em refazer tudo.

Atualmente, são utilizados softwares especializados para os trabalhos de cartografia temática. Todavia, o domínio de um software não implica em qualidade gráfica. Por isso, grande parte da produção gráfica atual apresenta problemas como os apresentados nesse artigo. Isto afeta todas as áreas do conhecimento.

Bons profissionais de cartografia temática automatizada fazem falta no mercado de trabalho. As editoras procuram técnicos qualificados, em particular para suas publicações didáticas e paradidáticas.

Nota dos Editores. As Figuras 5, 7 e 9, publicadas em tons de cinza com anuência da autora, são originalmente coloridas. 
LE SANN, J. G. (2005). Thematic cartography in geo-environmental research. Revista do Departamento de Geografia, n. 16, p. 61-69.

Abstract: This work presents Cartography as a language that represents facts and geographical phenomena. Thematic Cartography has specifications that interfere in the process of visual translation of geographical information. It emphasizes that the cartographer needs to know the graphic language and the limits of bi-dimensional representation in order to choose the visual variants compatible with the implicit meaning of the information to be translated. It analyzes and effectuates graphic corrections of several classic documents in scientific literature according to Semiology of Graphics. It presents and describes the method to structure the legend of a synthetic poly-thematic map applied to the case study of a diagnostic geo-environmental map of the Hydroelectric Power Igarapava Plant.

Key words: Thematic cartography; Geo-environmental research; Semiology of graphics; Geo-environmental cartography.

Recebido em 7 de setembro de 2005, aceito em 2 de outubro de 2005.

\section{Referências}

BERTIN, J. (1967) Semiologie graphique. Paris - Neuchatel: Mouton-Gauthiers-Villars. 431p.

BONIN, S. (1989) La graphique dans la presse. Paris,CFPJ. 175p.

CARMO, V.A. do (1994). Proposta gráfica para mapas politemáticos: o mapa diagnóstico geoambiental da Usina Hidrelétrica de lgarapava. Dissertação (Mestrado em Geografia) Instituto de Geociências, Universidade Federal de
Minas Gerais, Belo Horizonte: Universidade Federal de Minas Gerais, 77p.

GEORGE, P. (1970) Les méthodes de la Géographie. Paris: PUF, Coll. Que sais-je?

HAGGETT, P. (1973) L'analyse spatiale en géographie humaine. Paris: Armand Colin, Col. U. 391p. 